\title{
Storage Moduli of in situ Polymerised and Melt Extruded PA6 Graphite (G) Composites
}

\author{
Umar M. ${ }^{1}$, Ofem M. I. ${ }^{2} *$, Anwar A. S. ${ }^{1}$ and Usman M. M. ${ }^{3}$ \\ ${ }^{1}$ Department of Chemical Engineering, Kaduna Polytechnic, Kaduna State, Nigeria \\ ${ }^{2}$ Department of Mechanical Engineering, Cross River University of Technology, Calabar, Nigeria \\ ${ }^{3}$ Department of Chemical Engineering, Federal Polytechnic, Nasarawa, Nigeria \\ Corresponding Author: *michaeliofem@ crutech.edu.ng
}

https://doi.org/10.36263/nijest.2021.01.0252

\begin{abstract}
Four PA6/graphite $(G)$ composites systems were made. Two in situ polymerisation equivalent in mixing strain and two melt extrusion of equivalent processing strain. The effective modulus of the carbons, room temperature storage modulus and storage modulus at $80{ }^{\circ} \mathrm{C}$ were evaluated using Dynamic Mechanical and thermal Analysis (DMTA). Melt processing, was employed to make PA6/carbon composite systems over a range of loadings of Graphite $(G)$ and Graphite Nano Platelets (GNP) fillers. Melt extrusion was carried out using 100/6 processing condition, which indicates an extrusion screw rotation frequency of 100 rpm applied for 6 minutes (min) and 200/3 processing conditions, of $200 \mathrm{rpm}$ for $3 \mathrm{~min}$. For in situ polymerised systems $G$ and GNP dispersion was made using two similar conditions designated as 40/10 and 20/20. Here, 40/10 indicates that sonication amplitude of $40 \%$ was applied for $10 \mathrm{~min}$, whereas in the 20/20 conditions, amplitude of $20 \%$ was applied for $20 \mathrm{~min}$. For in situ Nano P INP 40/10 systems weak interaction between PA6 and GNP is indicated by the very low modulus enhancement above glass transition temperature $\left(T_{g}\right)$. The modulus behaviour shows that the reinforcement provided by GNP is not significant relative to unfilled PA6, despite the low loading levels. A similar, but less pronounced, behaviour is observed for INP 20/20 system. Effective modulus for the in situ polymerised systems INP 40/10, was $4.8 \mathrm{GPa}$. Due to the low loading level of GNP used and the better reaction rates, an extrapolated modulus of $22.4 \mathrm{GPa}$ is obtained in the INP 20/20 system. For G200/3 and G100/6 the trend of increasing modulus with GNP loading is not followed exactly. On all levels of loading, the relative modulus values of the INP 20/20 system are higher than those of the 40/10 system, a reflection of retention or improvement in the aspect ratio of the GNP due to less intensive sonication.
\end{abstract}

Keywords: In situ-polymerisation, Melt-extrusion, Effective-modulus, Storage-modulus

\subsection{Introduction}

Carbon can be used in different forms. Carbon Fibres, micro-particulates and nano-particulates are the common forms of carbon. To improve existing properties of carbon or develop an entire new properties, different processing techniques; melt, solution or in situ polymerisation can be applied (Keledi et al., 2012; Sengupta et al., 2011; Supova et al., 2011). The size-scale and structure of a particulate carbon are very important as these control the inherent properties. The dimensionality of the particulate carbon determines the structure in addition to whether it is pristine or modified. Different dimensional (1,2 or 3) structures of Particulate carbon fillers create room for wide range of alternatives for making carbon composites. Particulate carbons thus, provide a variety of carbon fillers suitable for polymer composites and whose basic building block is the graphene sheet.

The selection of an appropriate processing technique to make particulate carbon composites using well dispersed or percolated carbon filler will lead to desired properties. Properties such as light, weight and toughness may be maintained in addition to the good mechanical and electrical conductivity. The processing techniques determines the state of the filler in the composite following compounding; including dispersion - how well the filler is reduced down to its primary particles and 
distribution - the distance between neighbouring filler particles within the composite and how well the positions of the particles are randomised. Poor compounding frequently lead to agglomeration of filler displaying lower aspect ratio and surface area to volume ratio.

Graphite $(\mathrm{G})$, whether synthetic or natural, is mostly polycrystalline or granular. Due to anisotropy (Howe, 1952) properties graphite exhibits metallic and non-metallic properties concurrently (Wissler, 2006). Howe 1952, described $G$ as highly polycrystalline and anisotropic due to the difference between covalently bonded in-plane carbon networks and out-of-plane weak van der Waals forces (Sengupta et al., 2011). This makes it possible for small molecules to intercalate into the G galleries (Celzard et al., 2005) and also results in G being non-conductive out-of-plane since the layers in the stack are held only by weak van der Waals forces (Howe, 1952). The in-plane properties of G makes it stronger than diamond (Sengupta et al., 2011), semi-conductive, as well as thermally and electrically conductive.

This is why $\mathrm{G}$ is used for making polymer composites that are electrically (Clingerman 2001; Clingerman et al., 2002) and thermally (Weber et al., 2003; Miller et al., 2006) conductive. In contrast, the weak attraction out-of-plane has produced wide application for $\mathrm{G}$ as a solid lubricant. Therefore, polymer/G composites are specifically used in abrasion related applications regarding wear (Kang et al., 2003), tribology (Horský et al., 2001) and in evaluating performance of nanosized particulate carbons in polymer composites where $\mathrm{G}$ mainly serves as a control (Ramanathan et al., 2007; Debelak and Lafd, 2007). Despite the low cost of G, its limited use in advanced polymer composites perhaps has to do with its high density, $2.26 \mathrm{~g} / \mathrm{cm}^{3}$ (Sengupta et al., 2011) and very low aspect ratio (1.68-1.7) (Heiser et al., 2004) which may necessitate the use of higher loadings.

In the graphene family, graphite nano platelets (GNP) is widely employed because of its 2D structure, reasonably high aspect ratio (about 1500 (Kalaitzidou et al., 2007; Fukushima et al., 2006), high surface area (theoretically between $2630-2965 \mathrm{~m}^{2} / \mathrm{g}$ (Viculis et al., 2005) and chain segment constraining ability. Due to this, GNP have the potential to improve or induce multiple functions in polymers, such as a combination of improved barrier, mechanical, thermal and electrical functions, whilst at the same time retaining light weight and transparency (Li et al., 2011). However, the transfer of these properties to the matrix depends strongly on dispersion level, interaction and maintaining the size and shape of the GNP after processing (Sadasivuni et al., 2014). It is also possible to improve the aspect ratio of GNP by further exfoliation using techniques such as intercalation followed by polymerisation, oxidation, heat treatments and sonication. This will make GNP production cost effective compared to other nanocarbon fillers (Li et al., 2011).

Two graphitic platelet-structured carbon fillers were used in this research, graphite $(G)$ an example of micro-scale filler, and graphite nanoplatelets, (GNP) comparative nano-scale filler. The size scale of the fillers is considered in fixing the level of loading with that of the GNP-based nanocomposites being an order of magnitude lower than that of the G-based microcomposites. This is considered to be a better basis for comparison against the traditional (Ramanathan et al., 2007) same-weight comparison. The same weight comparison disregards the scale of interaction occurring in these diverse systems due to the significant disparity in surface area and aspect ratio between the two fillers. The disparity has significant implications for polymer/filler interactions and the property changes expected relative to the unfilled polymer matrix. The class of polymer matrix available to be selected from include the thermosets, elastomers or thermoplastics (amorphous or semi-crystalline) but this study is concerned with polyamide-6 (PA6)/particulate carbon composites. The semi-crystalline nature of PA6 and its strong intermolecular hydrogen bonding confers on it properties which suits applications such fibre, film and injection mouldings for engineering applications. In addition, its formation via ring-opening polymerisation provides the opportunity for processes such as casting, reaction injection moulding and vacuum-infusion of continuous fibre composites (all of which provide opportunity to construct complex shapes directly) (Van-Rijswijk et al., 2006).

Melt processing, which still maintains a lead in the commercial production of polymeric composites (Hussain et al., 2006), was employed using a twin-screw extruder, TSE, (Thermo-Haake Minilab) to make PA6/carbon composite systems over a range of loadings. Melt extrusion was carried out using $100 / 6$ processing condition, which indicates an extrusion screw rotation frequency of $100 \mathrm{rpm}$ applied for 6 minutes (min) and 200/3 processing conditions, of $200 \mathrm{rpm}$ for $3 \mathrm{~min}$. For in situ polymerised 
systems G and GNP dispersion was made using two similar conditions designated as 40/10 and 20/20. Here, 40/10 indicates that sonication amplitude of $40 \%$ was applied for $10 \mathrm{~min}$, whereas in the 20/20 conditions, amplitude of $20 \%$ was applied for 20 min. Comparing the acquired properties between melt extruded and in situ polymerised polymer/filler composites is not new (Tung et al., 2005), but here the comparisons are more extensive.

\subsection{Methodology}

\subsection{Materials}

Pristine commercial grade PA6 was donated by Akulun Germany. The monomer Epsilon Caprolactam $\left(\mathrm{C}_{6} \mathrm{H}_{11} \mathrm{NO}\right.$, coded as EC) was purchased from Sigma-Aldrich, with purity level of $99 \%$ and a molecular weight of 113.16. Pristine PA6 and EC were vacuum dried overnight at $50^{\circ} \mathrm{C}$ before usage which adequately removed moisture. Methyl Magnesium Bromide (coded as MMB, molecular weight 119.26,) is a Grignard catalyst precursor which forms the catalyst, (Caprolactam Magnesium Bromide (CMB)) in situ, was purchased Fisher Scientific as a $100 \mathrm{ml}$ bottle containing a $3.0 \mathrm{M}$ solution of MMB in diethyl ether. Activator or co-catalyst, is a mono-functional Nacetylcaprolactam $\left(\mathrm{C}_{8} \mathrm{H}_{13} \mathrm{NO}_{2}\right.$, coded as NAC), supplied by Sigma-Aldrich with purity of $99 \%$ and molecular weight of 155.19 . Graphite Filler: Synthetic graphite, (coded as G) is $\leq 2 \mu \mathrm{m}$ in particle size was supplied by SigmaAldrich. Graphite Nano-Platelets: GNP-15, (coded as GNP) with surface area $107 \pm 7 \mathrm{~m}^{2} / \mathrm{g}$, diameter of $15 \mu \mathrm{m}$, aspect ratio of 1500 and density of $2 \mathrm{~g} / \mathrm{cm}^{3}$ was bought from XG-Sciences, UK. Prior to use G and GNP were kept overnight in an oven at $160^{\circ} \mathrm{C}$.

\subsection{Method}

Details of experimental procedure for making the composites can be found elsewhere (Umar et al., 2020). Since storage modulus is obtained using Dynamic Mechanical and thermal Analysis (DMTA). DMTA is used to investigate the viscoelastic behaviour of polymers and composites by subjecting the test specimens to a dynamic sinusoidal stress or strain within a temperature range, a time frame or a frequency range. Melt processing, was employed to make PA6/carbon composite systems over a range of loadings of G and GNP fillers. Melt extrusion was carried out using 100/6 processing condition, which indicates an extrusion screw rotation frequency of $100 \mathrm{rpm}$ applied for 6 minutes (min) and 200/3 processing conditions, of $200 \mathrm{rpm}$ for $3 \mathrm{~min}$. For in situ polymerised systems $\mathrm{G}$ and GNP dispersion was made using two similar conditions designated as 40/10 and 20/20. Here, 40/10 indicates that sonication amplitude of $40 \%$ was applied for $10 \mathrm{~min}$, whereas in the 20/20 conditions, amplitude of $20 \%$ was applied for $20 \mathrm{~min}$. A TA Instruments Q800 dynamic mechanical analyser was used to determine the thermo-mechanical responses. Specimens (approximately $5.00 \mathrm{x} 1.55 \mathrm{x}$ $17.50 \mathrm{~mm}$ ) were cut from within the gauge length of injection moulded dog-bones made using Haake Minilab injection moulding machine. At least 3 specimens were tested for each material. The specimens were tested using single cantilever mode and applying a Poisson's ratio of 0.35 for PA6 and its composites. The tests were carried out using a temperature ramp/frequency sweep in multifrequency- strain operation mode, at a strain rate of $0.2 \%$, and a temperature ramp of $3^{\circ} \mathrm{C} / \mathrm{min}$ within the region of $0-200^{\circ} \mathrm{C}$. Five carbon loadings were made at equivalent incremental steps. For the micro composites, a G loading of 5-25 Wt.\% was used and for GNP composites, 0.5-2.5 Wt.\% were used.

\subsection{Results and Discussion}

\subsection{Storage modulus of the INP 40/10 and INP 20/20 systems}

Weak interaction between PA6 and GNP is indicated by the very low modulus enhancement above $T_{g}$ as can be seen in Figure $1 \mathrm{~A}$ and $1 \mathrm{~B}$ and from Table 1 (modulus at $80^{\circ} \mathrm{C}$ ). Although it is understood that the matrix-filler interaction is weak this may be compensated to some extent by the large surface area available with GNP-15 (Keledi et al., 2012), the wetting EC provides on GNP and any intercalation of EC between the carbon sheets (as established for EG (Pan et al., 2000). However, the modulus behaviour in Figure 1A shows that the reinforcement provided by GNP is not significant relative to unfilled PA6, although the loading levels are low. A similar, but less pronounced, behaviour is shown in Figure 1B. 

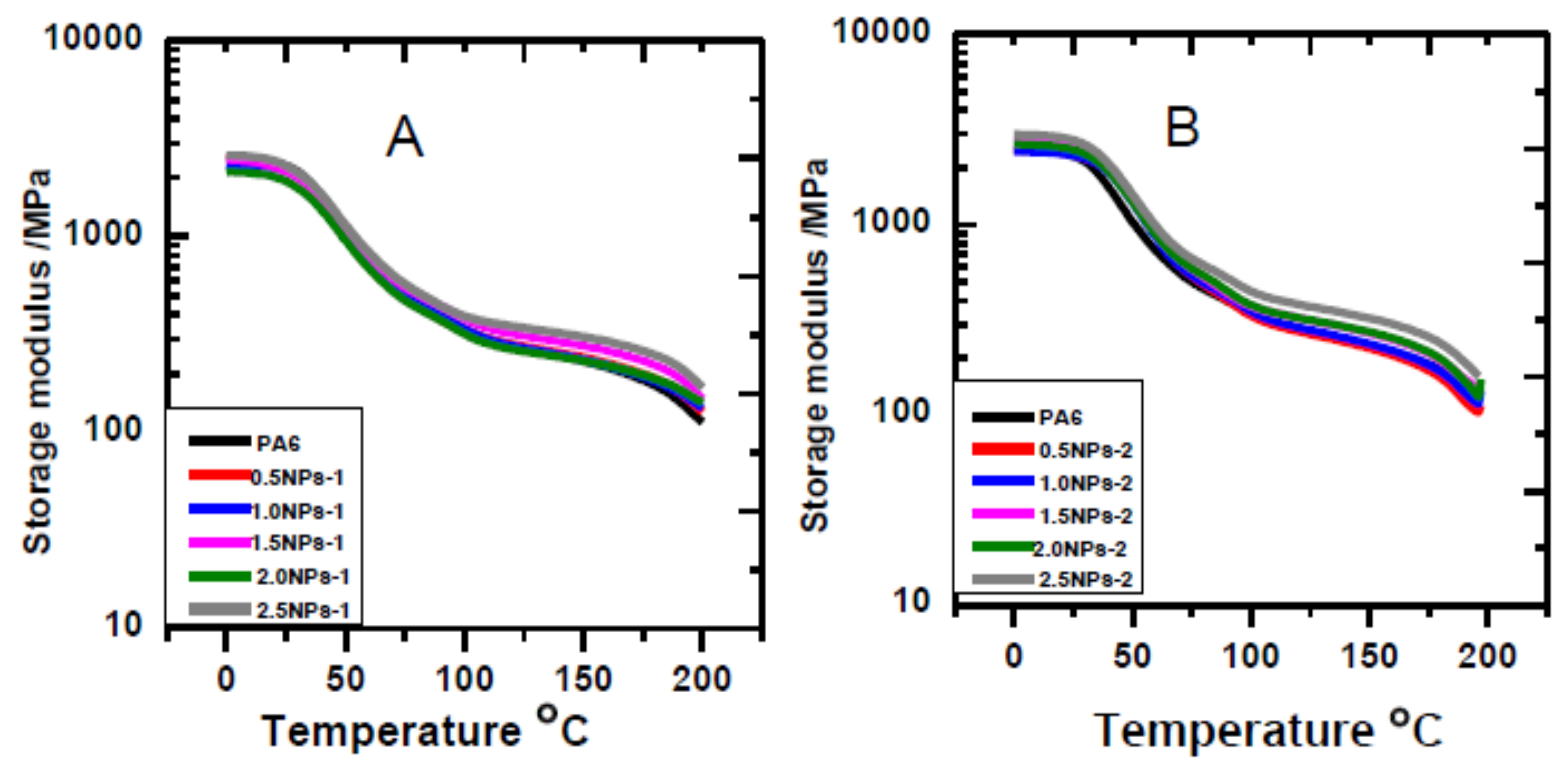

Figure 1: Storage modulus (E') versus temperature data for (A) INP 40/10 system where $40 \%$ indicates amplitude of sonication for $10 \mathrm{~min}$ and (B) for INP 20/20 system where 20\% indicates the amplitude of sonication for $20 \mathrm{~min}$. (INPs 40/10 (labelled-1) and INPs 20/20 (labelled-2) systems)

From Table 1, there appears to be slightly higher storage modulus reinforcement with the INP 20/20 system, probably due to better retention of the aspect ratio of the GNP. Attaining only low levels of modulus reinforcement with GNP loading has occurred with other systems, using epoxy and HDPE matrices (Pan et al., 2000; King et al., 2013) with the loading level used exceeding that of the present study. The fluctuation in E25 is attributed to effect of the diluents left after polymerisation especially in INP 40/10 system. This leads to a very poor effective modulus of GNP in INP 40/10 system of 4.8GPa after excluding the lowest modulus data of $1.9 \mathrm{GPa}$ corresponding to $2.0 \mathrm{GNP}$ wt. $\%$ loading. However, due to the low loading level of GNP used in the present work and the better reaction rates in the INP $20 / 20$ system, an extrapolated modulus of $22.4 \mathrm{GPa}$ is obtained. This value is higher by an order of magnitude relative to the $7.5 \mathrm{GPa}$ and $8.8 \mathrm{GPa}$ estimated for the IG $40 / 10$ and IG $20 / 20$ systems, respectively. The highest filler effective modulus for GNP occurs with the 20/20 processing regime. This may still reflect the influence of the aspect ratio of the smaller GNP particles since mild sonication with $20 \%$ amplitude for 20 min. may fragment the GNP particles such that its high aspect ratio is maintained. Direct horn sonication (Penu et al., 2010) (as used in present work) for only 10s was reported as sufficient to disperse CNT in molten EC and lowering in the rate of reaction was dependent both on exposure time and sonication amplitude. Some studies (Kalaitzidou et al., 2007; Fukushima et al., 2006) ascribe better mechanical property enhancement to smaller GNP fillers. However, in these synthesis systems, maintaining higher aspect ratio is expected to be a plus for mechanical property gains; whereas extrusion may cause folding, buckling and rolling of GNP-15 while GNP-5 maintains its lateral structure. Although higher aspect ratio is meant to be an advantage in terms of reinforcement, GNP-15 has been shown to be more flexible and easier to fold (Vadukumpully et al., 2011) which leads to loss of the original aspect ratio, shape and probably dimensionality. This event is more likely to occur in melt mixing processing. Extending similar extrapolation to the work by Ramanathan et al. (2007) on PMMA/GNP, where high modulus enhancements were obtained alongside increased $\mathrm{Tg}$, the effective modulus of GNP is 42.9GPa almost double what obtains here, (22.4GPa). The work of Vadukumpully et al. (2011) gave effective modulus of GNP of $65.8 \mathrm{GPa}$ which almost triples the best obtained in the present study in the INP 20/20 system. Notwithstanding, these results shows that the potential for impressive modulus improvements of PA6/GNP nanocomposites can be improved by tackling issues of dispersion, uncontrolled fragmentation (in the case of in situ polymerisation) and balancing up with optimised amounts of catalysing species to maintain high monomer conversion. Besides in the mentioned studies (Ramanathan et al., 2007; Vadukumpully et al., 2011) solution blending which ensures better retention of filler morphology was used. Additionally, Vadukumpully et al. (2011) modified the particle/polymer interaction to an organic/organic type which informs the greater interaction observed. 
Table 1: DMTA data for composites in the INP 40/10 (labelled-1) and INP 20/20 (labelled-2) systems

\begin{tabular}{|l|l|l|l|}
\hline GNP in situ polymerised & $\mathrm{E}^{\prime}$ at $25^{\circ} \mathrm{C} \mathrm{MPa}$ & $\mathrm{E}^{\prime}$ at $80^{\circ} \mathrm{C} \mathrm{MPa}$ & $\mathrm{T}_{\mathrm{g}}{ }^{\circ} \mathrm{C}$ (DMTA) \\
\hline PA6s & $2224 \pm 179$ & $440 \pm 39$ & $49.3 \pm 1.5$ \\
\hline $0.5 \mathrm{NPs}-1$ & $2355 \pm 393$ & $446 \pm 16$ & $50.0 \pm 0.9$ \\
\hline $1.0 \mathrm{NPs}-1$ & $2160 \pm 47$ & $465 \pm 29$ & $52.8 \pm 1.6$ \\
\hline $1.5 \mathrm{NPs}-1$ & $2354 \pm 194$ & $538 \pm 35$ & $53.8 \pm 1.3$ \\
\hline $2.0 \mathrm{NPs}-1$ & $1917 \pm 248$ & $434 \pm 63$ & $51.3 \pm 2.3$ \\
\hline $2.5 \mathrm{NPs}-1$ & $2305 \pm 18$ & $543 \pm 17$ & $51.8 \pm 1.6$ \\
\hline $0.5 \mathrm{NPs}-2$ & $2348 \pm 185$ & $499 \pm 46$ & $60.2 \pm 0.3$ \\
\hline $1.0 \mathrm{NPs}-2$ & $2311 \pm 148$ & $495 \pm 51$ & $58.2 \pm 0.8$ \\
\hline $1.5 \mathrm{NPs}-2$ & $2598 \pm 113$ & $543 \pm 36$ & $54.3 \pm 0.2$ \\
\hline $2.0 \mathrm{NPs}-2$ & $2497 \pm 157$ & $550 \pm 36$ & $56.5 \pm 1.8$ \\
\hline $2.5 \mathrm{NPs}-2$ & $2784 \pm 54$ & $613 \pm 10$ & $52.8 \pm 1.3$ \\
\hline
\end{tabular}

\subsection{Storage modulus of the NP 200/3 and NP100/6 systems}

Modulus versus temperature data for the GNP based melt processed system is shown in Figure 2A and $\mathrm{B}$ while the derived data are presented in Table 2. Compared to the synthesized systems (Section 3.1 ), it can be seen that the trend of increasing modulus with GNP loading is not followed exactly though there is some resemblance. The major difference between the two systems is the grouping of $T_{g}$ in A and its broad division into two groups in B, which was discussed previously in Section 3.1.
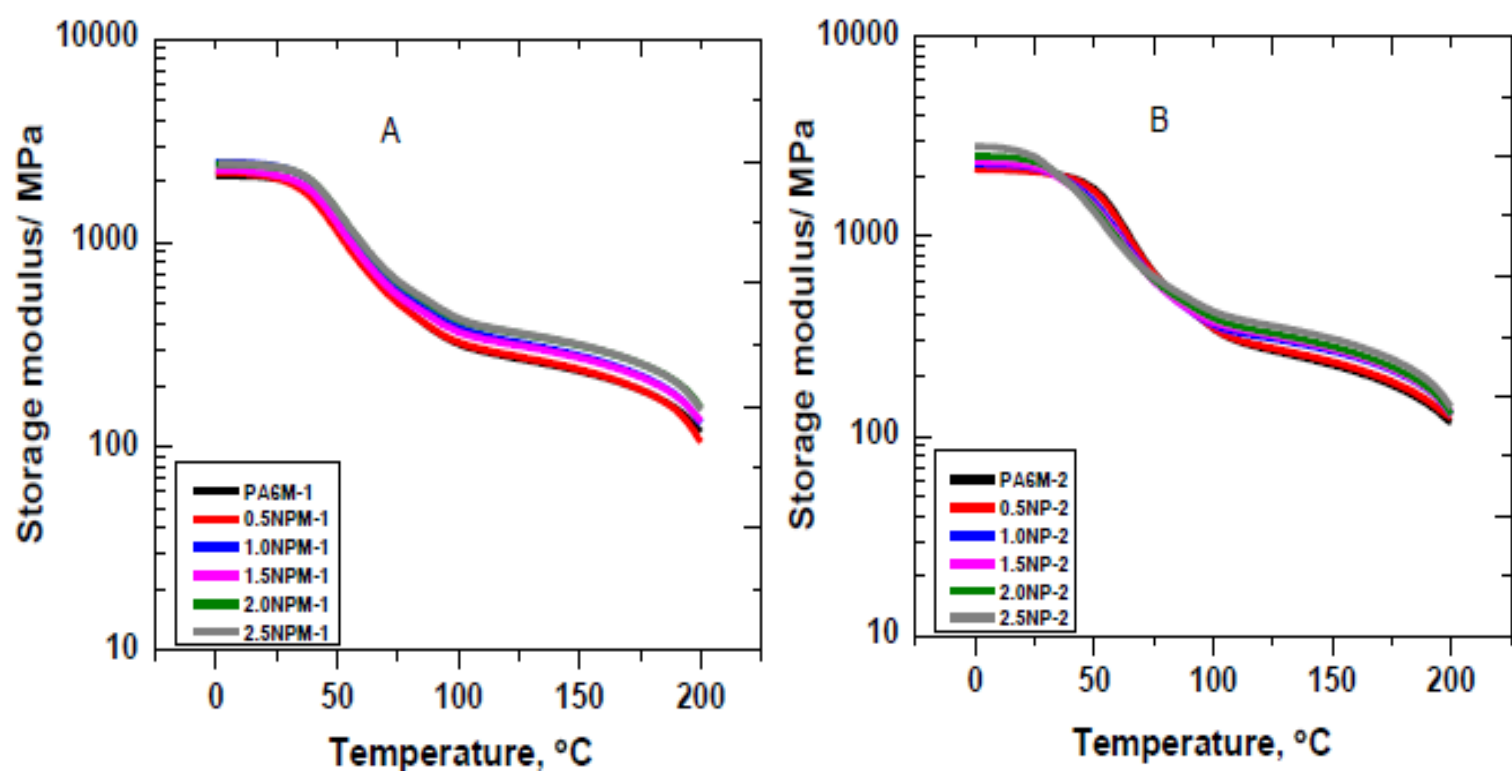

Figure 2: Storage modulus (E') versus temperature data for (A) NP 200/3 (screw speed of $200 \mathrm{rpm}$ for $3 \mathrm{~min}$ ) and (B) NP 100/6 (screw speed of $100 \mathrm{rpm}$ for $6 \mathrm{~min}$ ) systems. (NPM 200/3 (labelled-1) and NPM 100/6 (labelled-2) systems)

Table 2: DMTA derived data for composites in NP 200/3 (labelled 1) and NP100/6 (labelled 2) systems

\begin{tabular}{|l|l|l|l|}
\hline GNP melt extruded nanocomposites & $\mathrm{E}^{\prime}$ at $25^{\circ} \mathrm{C} \mathrm{MPa}$ & $\mathrm{E}^{\prime}$ at $80^{\circ} \mathrm{C}$ & $\mathrm{T}_{\mathrm{g}}{ }^{\circ} \mathrm{C}(\mathrm{DMTA})$ \\
\hline PA6M-1 & $2066 \pm 50$ & $461 \pm 39$ & $58.2 \pm 4.2$ \\
\hline $0.5 \mathrm{NPM}-1$ & $2069 \pm 78$ & $454 \pm 26$ & $54.7 \pm 0.3$ \\
\hline $1.0 \mathrm{NPM}-1$ & $2371 \pm 223$ & $539 \pm 42$ & $54.2 \pm 0.3$ \\
\hline $1.5 \mathrm{NPM}-1$ & $2154 \pm 10$ & $502 \pm 36$ & $55.7 \pm 0.0$ \\
\hline $2.0 \mathrm{NPM}-1$ & $2338 \pm 120$ & $579 \pm 29$ & $56.5 \pm 0.9$ \\
\hline $2.5 \mathrm{NPM}-1$ & $2357 \pm 141$ & $591 \pm 24$ & $56.3 \pm 0.6$ \\
\hline PA6M-2 & $2124 \pm 126$ & $562 \pm 21$ & $67.7 \pm 0.6$ \\
\hline $0.5 \mathrm{NPM}-2$ & $2104 \pm 121$ & $558 \pm 30$ & $66.7 \pm 0.6$ \\
\hline $1.0 \mathrm{NPM}-2$ & $2207 \pm 83$ & $531 \pm 74$ & $65.0 \pm 1.7$ \\
\hline $1.5 \mathrm{NPM}-2$ & $2240 \pm 54$ & $527 \pm 10$ & $64.7 \pm 0.6$ \\
\hline $2.0 \mathrm{NPM}-2$ & $2357 \pm 40$ & $533 \pm 9$ & $63.0 \pm 1.0$ \\
\hline $2.5 \mathrm{NPM}-2$ & $2500 \pm 151$ & $572 \pm 17$ & $60.8 \pm 0.8$ \\
\hline
\end{tabular}




\subsection{Room temperature storage moduli (E25) of the INP 40/10 and INP 20/20 systems}

The INP 40/10 system shows no significant changes in E25 for the nanocomposites relative to unfilled PA6 as shown in Figure 3A. However, it is observed, that $1.5 \mathrm{NP}-1$ nanocomposite has the highest $T_{g}$ and E25, which relate to their higher reaction rate that raises the number of reaction activation sites (Van-Rijswijk et al., 2006) and eventually leads to increased crystallinity and modulus. E25 drops at 2.0 NP wt. \% loading and rises again at 2.5GNP wt. \% loading in both the INP 40/10 and INP 20/20 systems. This reflects the dynamics of mixing (stirring and dispersion by sonication) imparted on the GNP particles as its loading level increases in molten EC. The efficiency of dispersion by sonication is not independent of loading (Hielscher, 2005) and the extent of particle deagglomeration, dispersion and fragmentation attained depends on the mixing dynamics. Therefore, the mechanical properties of nanocomposites reflect the dispersed state and the interfacial contact (Gao et al., 2006) with the polymer. In addition, processing using in situ polymerisation without washing to remove remnants of catalysing species or unconverted EC means that plasticization cannot be entirely ruled out.

The INP 20/20 system shows higher E25 values relative to the INP 40/10 system due to better wetting of GNP by EC and retention of the GNP aspect ratio. When composites of parallel loading are compared (Table 1), a semblance of a pattern is seen with nanocomposites in the INP 40/10 system reflecting the stepping-up of the mole $\%$ of catalysing species, thus preventing the fall in rate of reaction. It is possible to improve the physical properties of PA6 by changing the catalysing specie concentrations (Tüzün, 2008). However, the effective modulus of GNP filler in INP 20/20 system estimate as $22.4 \mathrm{GPa}$ and that of INP $40 / 10$ system being only $4.8 \mathrm{GPa}$ probably indicates poor GNP morphology and aspect ratio of the GNP (due to the sonication condition applied). The effective GNP modulus value of $22.4 \mathrm{GPa}$ for INP 20/20 is in the same order of magnitude with that of GO (32GPa) and GNP (42GPa) measured in the tensile mode (Dikin et al., 2007) However, the effective modulus of GNP in INP 20/20 system is much lower than the theoretical value of 1TPa reported for pristine graphene (Geim and Novoselov, 2007). The value is, notwithstanding, higher than the values estimated for $\mathrm{G}$ in all the $\mathrm{G}$ based systems.
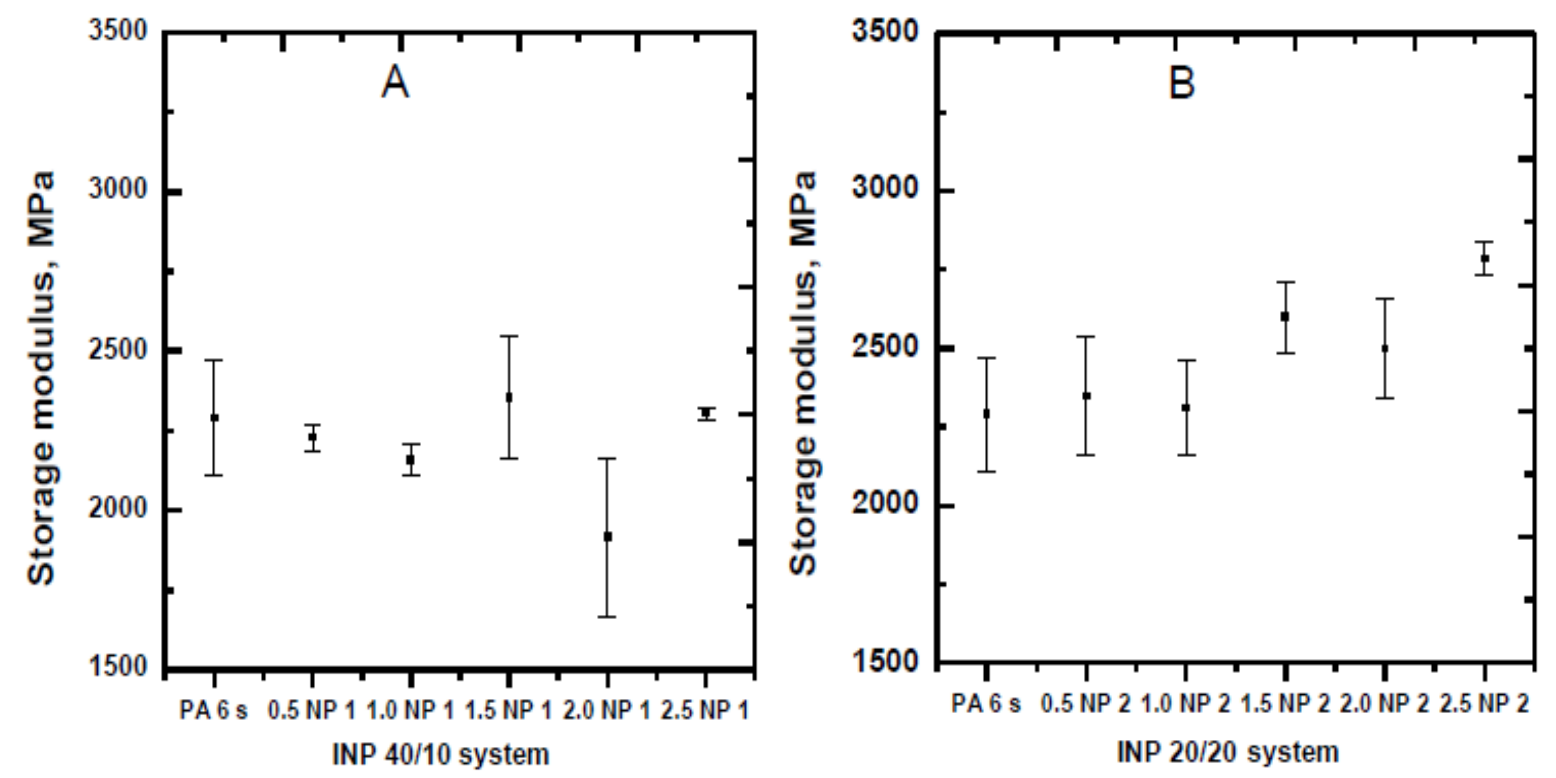

Figure 3: Room temperature storage modulus in (A) INP 40/10 and (B) INP 20/20 systems. INP $40 / 10$ indicates $40 \%$ amplitude of sonication for $10 \mathrm{~min}$ and INP 20/20 indicates $20 \%$ amplitude for $10 \mathrm{~min}$

\subsection{Room temperature storage moduli (E25) of the INP 200/3 and INP 100/6 systems}

Figure 4 presents the E25 of the PA6/GNP melt extruded systems. Unlike in the synthesized system, in both systems the standard deviation bars from $2.0 \mathrm{NP}$ wt. \% loading do not overlap with the two unfilled PA6 matrices. In Figure 4A for INP 200/3 system, with the exception of 0.5 GNP wt. \% loading, all other loadings show higher average modulus compared to unfilled PA6. This probably indicates that the rigour associated with the 200/3 processing regime causes GNP to fragment as suggested by (Fukushima et al., 2006). A response which coincides somewhat with the expected 
reinforcing effect of GNP is depicted in Figure 4B for the INP 100/6 system. This puts into context the effect of processing with these two melt extrusion regimes of the same magnitude in strain history. Literature has shown the capability of GNP as a heterogeneous improver of matrix properties as reviewed in these works (Ramanathan et al., 2007; Wang et al., 2010; Vadukumpully et al., 2011; Kim et al., 2010). Here the effective moduli of GNP obtained are 13.8GPa in NP 200/3 system and 17.3GPa in NP 100/6 system. A difference of 3.5 GPa reflecting the superiority in maintaining the aspect ratio of GNP in NP 100/6 the processing regime where a lesser GNP crumbling rigour is applied. These two GNP effective moduli values fall below that obtained in the INP 20/20 system, which is $22.4 \mathrm{GPa}$. Thus, upholding superior interaction and dispersion ability of the GNP in the in situ polymerisation system with higher reaction rates and a lesser sonication power, which has a lesser fragmenting effect. The moduli values obtained in present study are normalised relative to their respective matrix and compared with those of polymer/GNP-15 nanocomposites from other studies (Ramanathan et al., 2007; Biswas et al., 2011) and is presented in Figure 5A and 5B.
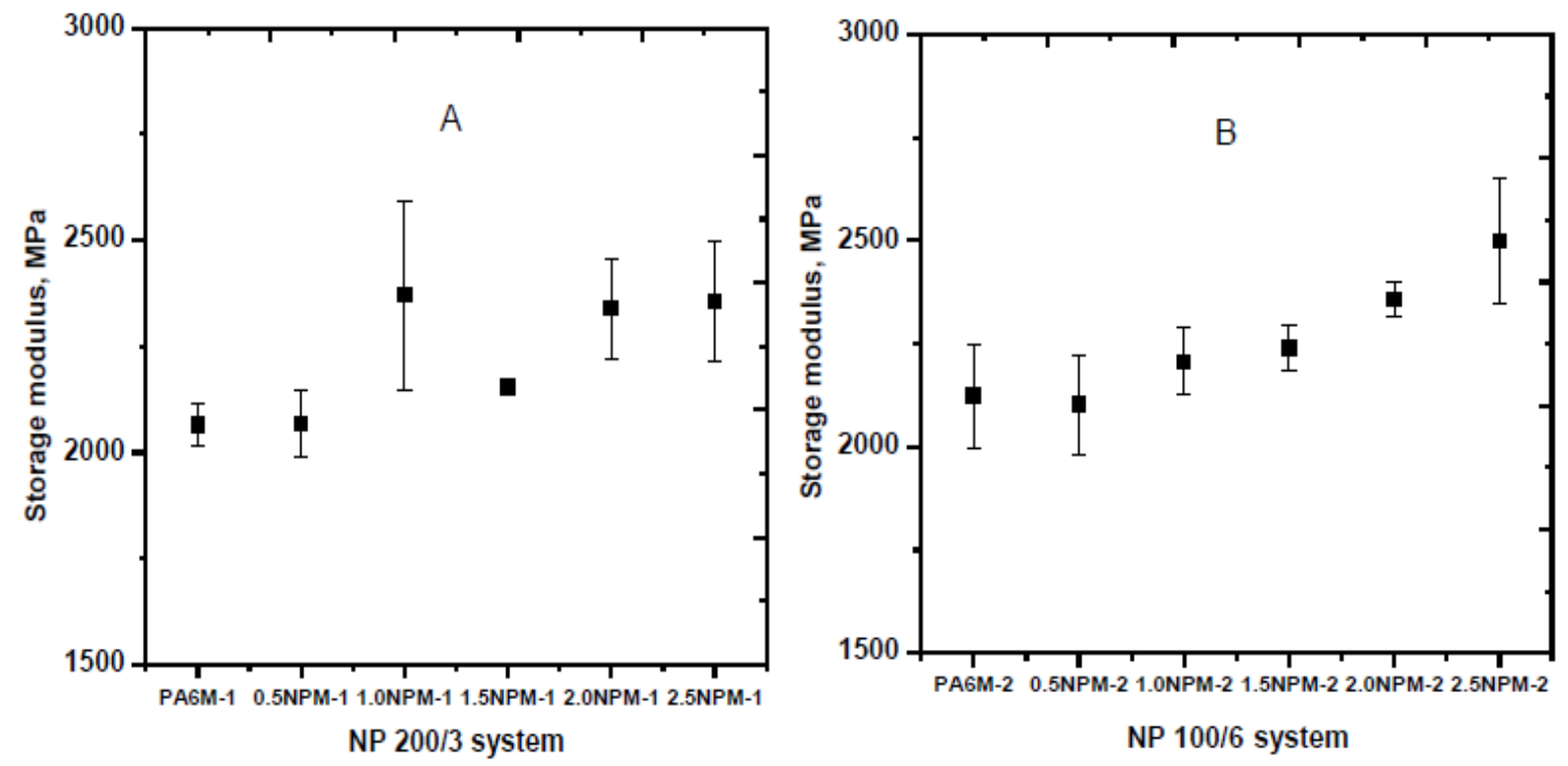

Figure 4: Room temperature storage modulus for (A) NP 200/3 (screw speed of $200 \mathrm{rpm}$ for $3 \mathrm{~min}$ ) and (B) NP 100/6 (screw speed of $100 \mathrm{rpm}$ for $6 \mathrm{~min}$ ) systems

In Figure 5A, the data for the INP 40/10 and INP 20/20 systems show that while modulus fluctuates with GNP loading in the former, in the latter the fluctuations are minimal. While the fluctuations may be ascribed to the reaction inhibiting effect of the GNP, which causes the ratio of catalysing species to be increased, it remains more likely to impact the INP 40/10 system because of the higher number of particle breakages imposed by harsh sonication conditions, which makes more surfaces available ( $\mathrm{Li}$ et al., 2007). The end result points to an increase towards the tendency of carbon fillers to inhibit reaction (Horský et al., 2001; Penu et al., 2010; Horský et al., 2003; Horský et al., 1999). On all levels of comparison, the relative modulus values of the INP 20/20 system are higher than those of the $40 / 10$ system, which reflects retention or even improvement in the aspect ratio of the GNP (due to less intensive sonication). Some E25 values from literature are higher than those of the present study, principally due to the difference in processing. With regards to Figure 5A, the work of Ramanathan et al. (2007) and Biswas et al. (2011) both used solution mixing which provides a good interfacial contact and retention of the GNP morphology. Ramanathan et al. (2007) showed that GNP, like other nano-carbon particulate fillers, can improve polymer mechanical properties at low loading fractions if good interfacial contact occurs. Biswas et al. (2011) using a liquid crystalline polymer (LCP) also found relatively higher E25 compared to an INP 20/20 system, although at $2.5 \mathrm{GNP}$ wt. \% loading. The authors ascribed the E25 enhancement to both good dispersion and to processing, using a doctor blade to distribute and align the GNP particles thereby leading to better reinforcement. Comparison with higher GNP loading is restricted since even the loading level of $2.5 \mathrm{GNP}$ wt. \% was only achieved in the present study by increasing the mole \% of the catalysing species.

In Figure 5B, the melt extruded systems; (NP 200/3 and NP 100/6) are compared with the same system as in Figure 5A. Ramanathan et al. (2007) PMMA based system again excelled in relative 
modulus improvement while comparatively both NP 200/3 and NP 100/6 systems are similar to Biswas et al. (2011) study. Increases in relative modulus values are common upon filling polymers with particulate carbons. Krupta et al. (2001) studied expanded graphite (EG) composites with HDPE and LDPE and obtained more than 5 fold modulus increase at $0.5 \mathrm{wt}$. \% of EG. Chandrasekaran et al. (2013) showed the relative modulus of an epoxy/GNP composite increased to the highest modulus ratio of 1.16 at $0.5 \mathrm{wt}$. \%. However, at 1 and 2 GNP wt. \% loading, the modulus ratios were only 1.09, and 1.14, respectively. This behaviour was suggested to occur due to percolation of GNP at the lower $(0.5 \mathrm{GNP}$ wt. \%) loading level, which also led to a reduced $\tan \delta$ peak value and indicated additional constraint relative to the higher loading levels. It was also observed that the modulus value corresponding to $T_{g}$ also dropped compared to other nanocomposites.
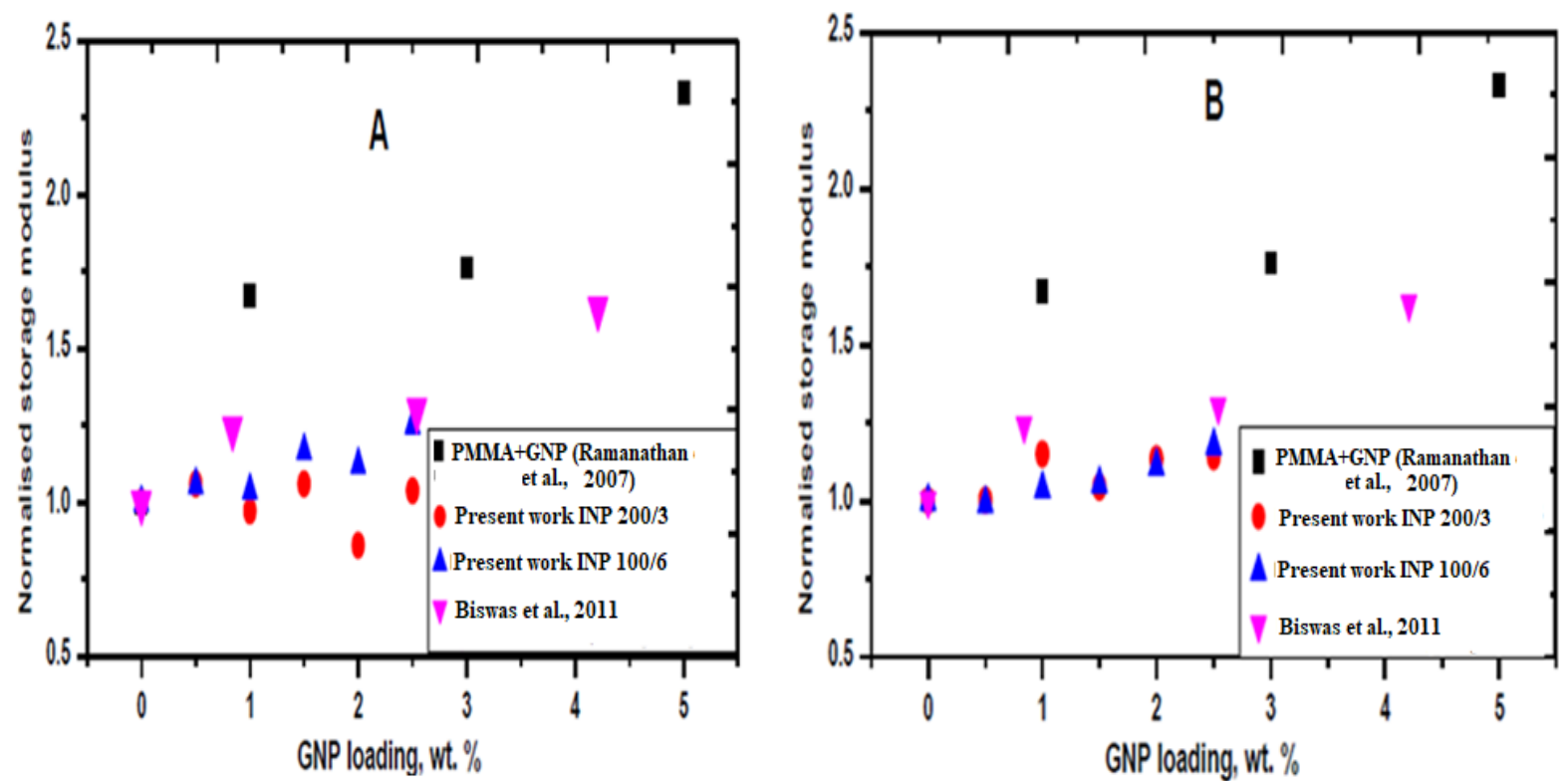

Figure 5: Comparison of storage moduli of (A) INP 40/10 and INP 20/20 (where 40/10 indicate $40 \%$ amplitude of sonication for $10 \mathrm{~min}$ and $20 \%$ amplitude for $10 \mathrm{~min}$ ) and (B) G 200/3 and G 100/6 (where G 200/3 indicates screw speed of $200 \mathrm{rpm}$ for $3 \mathrm{~min}$ and G 100/6 screw speed of $100 \mathrm{rpm}$ for 6 min ), both of which are compared with storage moduli from literature (Ramanathan et al., 2007;

Biswas et al., 2011)

\subsection{Conclusion}

PA6 fibres reinforced GNP nano-composites were successfully prepared by in situ polymerisation and melt extrusion methods. The storage moduli of the nano-composites were evaluated at $25^{\circ} \mathrm{C}$ (E25) and $80^{\circ} \mathrm{C}$ (E80). For INP 200/3 system, with the exception of 0.5 GNP wt. \% loading, all other loadings show higher average modulus compared to unfilled PA6. An indication that the rigour associated with the 200/3 processing regime causes GNP to fragment. The effective moduli of GNP obtained are 13.8GPa in NP 200/3 system and 17.3GPa in NP 100/6 system. A difference of 3.5GPa reflecting the superiority in maintaining the aspect ratio of GNP in NP 100/6, the processing regime where a lesser GNP crumbling rigour is applied. These two GNP effective moduli fall below that obtained in the INP 20/20 system, which is 22.4GPa. Thus, upholding superior interaction and dispersion ability of the GNP in the in situ polymerisation system with higher reaction rates and a lesser sonication power, which has a lesser fragmenting effect. There was fluctuation in moduli with GNP loading for the INP 40/10 but minimal for INP 20/20 systems. While the fluctuations may be ascribed to the reaction inhibiting effect of the GNP, which causes the ratio of catalysing species to be increased, it is more likely to impact the INP 40/10 system because of the higher number of particle breakages imposed by harsh sonication conditions, which makes more surfaces available. On all levels of assessment, the relative modulus of the INP 20/20 system are higher than those of the 40/10 system, a reflection of the retention or improvement in the aspect ratio of the GNP. 


\section{References}

Biswas, S., Fukushima, H. and Drzal, L. T. (2011). Mechanical and electrical property enhancement in exfoliated graphene nanoplatelet/liquid crystalline polymer nanocomposites. Composites Part A: Applied Science and Manufacturing, 42(4), pp. 371-375.

Chandrasekaran, S., Seidel, C. and Schulte, K. (2013). Preparation and characterization of graphite nano-platelet (GNP)/epoxy nano-composite: Mechanical, electrical and thermal properties. European Polymer Journal, 49(12), pp. 3878-3888.

Celzard, A., Mareche, J. and Furdin, G. (2005). Modelling of exfoliated graphite. Progress in Materials Science, 50(1), pp. 93-179.

Clingerman, M. L. (2001). Development and modelling of electrically conductive composite materials: Michigan Technological University.

Clingerman, M. L., Weber, E. H., King, J. A. and Schulz, K. H. Synergistic effect of carbon fillers in electrically conductive nylon 6, 6 and polycarbonate based resins. Polymer Composites, 23(5), pp. 911-924.

Debelak, B. and Lafdi, K. (2007). Use of exfoliated graphite filler to enhance polymer physical properties. Carbon, 45(9), pp. 1727-3174.

Dikin, D. A., Stankovich, S., Zimney, E. J., Piner, R. D., Dommett, G. H., Evmenenko, G., et al. (2007). Preparation and characterization of graphene oxide paper. Nature, 448(7152), pp. 457-460.

Fukushima, H., Drzal, L., Rook, B. and Rich, M. (2006). Thermal conductivity of exfoliated graphite nanocomposites. Journal of Thermal Analysis and Calorimetry, 85(1), pp. 235-238.

Gao, J., Zhao, B., Itkis, M. E., Bekyarova, E., Hu, H., Kranak, V., et al. (2006). Chemical Engineering of the Single-Walled Carbon Nanotube-Nylon 6 Interface. Journal of the American Chemical Society, 128(23), pp. 7492-7496.

Geim, A. K. and Novoselov, K. S. (2007). The rise of graphene. Nature Materials, 6(3), pp. 183-191.

Hielscher, T. (2005). Ultrasonic production of nana-size dispersions and emulsion. ENS'05, Paris, France.

Howe, J. P. (1952). Properties of Graphite. Journal of the American Ceramic Society, 35(11), pp. 275283.

Horský, J., Kolařík, J. and Fambri, L. (2003). One-Step Synthesis of Hybrid Composites of Poly (6hexanelactam) Combining Solid Tribological Additives and Reinforcing Components. Macromolecular Materials and Engineering, 288(5), pp. 421-431.

Horský, J., Kolařík, J. and Fambri, L. (1999). Composites of alkaline poly (6-hexanelactam) with solid lubricants: one-step synthesis, structure, and mechanical properties. Die Angewandte Makromolekulare Chemie, 271(1), pp. 75-83.

Horský, J., Kolařík, J. and Fambri, L. (2001). Gradient Composites of Alkaline Poly (6-hexanelactam) with Graphite: One-Step Synthesis, Structure, and Mechanical Properties. Macromolecular Materials and Engineering, 286(4), pp. 216-224.

Heiser, J. A., King, J. A., Konell, J. P., Miskioglu, I. and Sutter, L. L. (2004). Tensile and impact properties of carbon filled nylon-6,6 based resins. Journal of Applied Polymer Science, 91(5), pp. 2881-2893. 
Hussain, F., Hojjati, M., Okamoto, M. and Gorga, R. E. (2006). Polymer-matrix nanocomposites, processing, manufacturing, and application: an overview. Journal of Composite Materials, 40(17), pp. 1511-1575.

Kang, S-C. and Chung, D-W. (2003). Improvement of frictional properties and abrasive wear resistance of nylon/graphite composite by oil impregnation. Wear, 254(1), pp. 103-110.

Keledi, G., Hári, J. and Pukánszky, B. (2012). Polymer nanocomposites: structure, interaction, and functionality. Nanoscale, 4(6), pp. 1919-1938.

Kalaitzidou, K., Fukushima, H. and Drzal, L. T. (2007). Multifunctional polypropylene composites produced by incorporation of exfoliated graphite nanoplatelets. Carbon, 45(7), pp. 1446-1452.

Kim, S., Seo, J. and Drzal, L. T. (2010). Improvement of electric conductivity of LLDPE based nanocomposite by paraffin coating on exfoliated graphite nanoplatelets. Composites Part A: Applied Science and Manufacturing, 41(5), pp. 581-587.

Krupa, I. and Chodák, I. (2001). Physical properties of thermoplastic/graphite composites. European Polymer Journal, 37(11), pp. 2159-2168.

King, J. A., Klimek, D. R., Miskioglu, I. and Odegard, G. M. (2013). Mechanical properties of graphene nanoplatelet/epoxy composites. Journal of Applied Polymer Science, 128(6), pp. 4217-4223.

Li, J., Sham, M. L., Kim, J-K. and Marom, G. (2007). Morphology and properties of UV/ozone treated graphite nanoplatelet/epoxy nanocomposites. Composites Science and Technology, 67(2), pp. 296-305.

Li, B. and Zhong, W-H. (2011). Review on polymer/graphite nanoplatelet nanocomposites. Journal of Materials Science, 46(17), pp. 5595-5614.

Miller, M. G., Keith, J. M., King, J. A., Hauser, R. A. and Moran, A. M. (2006). Comparison of the guarded-heat-flow and transient-plane-source methods for carbon-filled nylon 6, 6 composites: Experiments and modeling. Journal of Applied Polymer Science, 99(5), pp. 2144-2151.

Pan, Y. X., Yu, Z. Z., Ou, Y. C. and Hu, G. H. (2000). A new process of fabricating electrically conducting nylon 6/graphite nanocomposites via intercalation polymerization. Journal of Polymer Science Part B: Polymer Physics, 38(12), pp. 1626-1633.

Penu, C., Hu, G. H., Fonteix, C., Marchal, P. and Choplin, L. (2010). Effects of carbon nanotubes and their state of dispersion on the anionic polymerization of $\epsilon$-caprolactam: 1. Calorimetry. Polymer Engineering \& Science, 50(12), pp. 2287-2297.

Ramanathan, T., Stankovich, S., Dikin, D., Liu, H., Shen, H., Nguyen, S., et al. (2007). Graphitic nanofillers in PMMA nanocomposites - an investigation of particle size and dispersion and their influence on nanocomposite properties. Journal of Polymer Science Part B: Polymer Physics, 45(15), pp. 2097-2112.

Sadasivuni, K. K., Ponnamma, D., Thomas, S. and Grohens, Y. (2014). Evolution from graphite to graphene elastomer composites. Progress in Polymer Science, 39(4), pp. 749-780.

Sengupta, R., Bhattacharya, M., Bandyopadhyay, S. and Bhowmick, A. K. (2011). A review on the mechanical and electrical properties of graphite and modified graphite reinforced polymer composites. Progress in Polymer Science, 36(5), pp. 638-670.

Supova, M., Martynkova, G. S. and Barabaszova, K. (2011). Effect of nanofillers dispersion in polymer matrices: a review. Science of Advanced Materials, 3(1), pp. 1-25. 
Tung, J., Gupta, R., Simon, G., Edward, G. and Bhattacharya, S. (2005). Rheological and mechanical comparative study of in situ polymerized and melt-blended nylon 6 nanocomposites. Polymer, 46(23), pp. 10405-10418.

Tüzün, F. N. (2008). Effect of the Activator Type and Catalyst/Activator Ratio on Physical and Mechanical Properties of Cast PA-6. Polym Plast Technol Eng., 47(5), pp. 532-5341.

Umar, M., Ofem, M. I., Anwar, A. S. and Salisu, A. G. (2020). Thermo gravimetric analysis (TGA) of PA6/G and PA6/GNP composites using two processing streams. Journal of King Saud University Engineering Sciences, doi.org/10.1016/j.jksues.2020.09.003 (in the press).

Vadukumpully, S., Paul, J., Mahanta, N. and Valiyaveettil, S. (2011). Flexible conductive graphene/poly (vinyl chloride) composite thin films with high mechanical strength and thermal stability. Carbon, 49(1), pp. 198-205.

Van Rijswijk, K., Bersee, H., Beukers, A., Picken, S. and Van Geenen, A. (2006). Optimisation of anionic polyamide- 6 for vacuum infusion of thermoplastic composites: Influence of polymerisation temperature on matrix properties. Polymer Testing, 25(3), pp. 392-404.

Van Rijswijk, K., Bersee, H., Jager, W. and Picken, S. Optimisation of anionic polyamide-6 for vacuum infusion of thermoplastic composites: choice of activator and initiator. Composites Part A: Applied Science and Manufacturing, 37(6), pp. 949-956.

Viculis, L. M., Mack, J. J., Mayer, O. M., Hahn, H. T. and Kaner, R. B. Intercalation and exfoliation routes to graphite nanoplatelets. Journal of Materials Chemistry, 15(9), pp. 974-978.

Wang, L., Hong, J. and Chen, G. (2010). Comparison study of graphite nanosheets and carbon black as fillers for high density polyethylene. Polymer Engineering \& Science, 50(11), pp. 2176-2181.

Weber, E. H., Clingerman, M. L. and King, J. A. (2003). Thermally conductive nylon 6,6 and polycarbonate based resins. I. Synergistic effects of carbon fillers. Journal of Applied Polymer Science, 88(1), pp. 112-122.

Wissler, M. (2006). Graphite and carbon powders for electrochemical applications. Journal of Power Sources, 156(2), pp. 142-150.

Cite this article as:

Umar M., Ofem M. I., Anwar A. S. and Makama A. B. 2021. Storage Moduli of in situ Polymerised and Melt Extruded PA6 Graphite (G) Composites. Nigerian Journal of Environmental Sciences and Technology, 5(1), pp. 91-101. https://doi.org/10.36263/nijest.2021.01.0252 